\title{
DISCURSO OFICIAL Y DERECHOS HUMANOS EN EL OPERATIVO Conjunto Chihuahua
}

\section{LAURA RUIZ \\ LUIS LARA}

\section{RESUMEN}

T a intención de este trabajo es señalar cómo el discurso de los derechos humanos se ha convertido en un campo de batalla ideológico, desarrollado de manera especial en el escenario político y cultural entre aquellos que, ubicándose como los responsables de proveer seguridad a la población, han implementado una estrategia de combate a la criminalidad que se ha traducido en una violación sistemática a los derechos humanos y quienes, por otro lado, han señalado que la guerra ha sido solo un pretexto para implementar una serie de políticas que llevan a la contención y represión social. Si bien, lamentablemente, son diversos los casos de violaciones a los derechos humanos en la historia de nuestro país, nuestra intención aquí es plantear una serie de apuntes respecto al discurso que inhibe y se desinteresa por trazar acciones en respeto de los derechos humanos, tomando por caso lo acontecido en Ciudad Juárez en el marco del Operativo Conjunto Chihuahua (occH).

Palabras clave: Configuración cultural, discurso oficial, derechos humanos, Operativo Conjunto Chihuahua 


\section{INTRODUCCIÓN}

El discurso de los derechos humanos puede ser visualizado como un espacio de configuración cultural. Configuración, porque dicho discurso no se limita al área de debate de los derechos humanos, sino que tiene que ver con los modos de hacer política desde distintos medios y escenarios sociales, lo cual se integra en una lucha por el sentido social, en este caso el ejercicio desde una semántica y ubicación como guerra contra la criminalidad declarada desde el Estado, donde hubo daños colaterales y vulneración de los derechos humanos. Son algunos sacrificios que debemos pagar en aras de nuestra seguridad.

En este tenor, el ejercicio lo dividimos en dos apartados: en el primero se hace una breve presentación de lo que fue el Operativo Conjunto Chihuahua, que tuvo como uno de sus principales escenarios a Ciudad Juárez, y algunas de sus implicaciones en el respeto de los derechos humanos; en un segundo momento, procuramos presentar algunos de los elementos que dominaron el discurso oficial. En concreto, en la vigencia y sentido que a estos se buscó otorgar.

\section{EL OPERATIVO CONJUNTO CHIHUAHUA Y LOS DERECHOS HUMANOS ${ }^{1}$}

A su llegada a la Presidencia de la República (2006), Felipe Calderón Hinojosa implementó una serie de operativos conjuntos en el marco de su lucha contra el narcotráfico y el crimen organizado que abarcaron gran parte del país, los cuales estuvieron encabezados por elementos del Ejército Mexicano y la Policía Federal. Abarcando los estados de Guerrero, Michoacán, Baja California, Sinaloa, Nuevo León, Tamaulipas, Durango y Chihuahua. Así, tratar de entender que ocurrió en Ciudad Juárez en el marco del Operativo Conjunto Chihuahua no puede ser visto de manera aislada de lo que aconteció en dicho periodo en otros entidades del país, donde una de las constantes, además de una escalada de muer-

1 En este subtema se contó con la colaboración del sociólogo Eric Urizar. 
tes violentas asociadas a la guerra contra el crimen organizado (Escalante, 2011, Merino, 2011), se vivió un fuerte incremento de personas desaparecidas y desplazadas, así como un despunte en denuncias por violaciones a los derechos humanos en contra de los diferentes cuerpos policiacos y militares.

El Operativo Conjunto Chihuahua se implementó desde el gobierno federal con la anuencia del gobierno estatal y municipal. Dicho operativo fue dado a conocer a la opinión pública en Ciudad Juárez el mes de marzo del 2008, junto con la llegada de un importante número de elementos del Ejército Mexicano que vinieron a tomar control de la ciudad con el supuesto fin de regresarle la tranquilidad que el crimen le había arrebatado.

De la importancia de estos operativos versus el crimen organizado da cuenta la entrevista realiza por Jorge Zepeda Paterson al Presidente Calderón:

El crimen organizado busca el control territorial, será una guerra sin cuartel porque ya no hay posibilidad de convivir con el narco. No hay regreso; son ellos o nosotros. [...] La estrategia está planteada sobre dos horizontes: uno de muy corto plazo que consiste en reposicionar la autoridad y la potestad del Estado mediante la movilización de la fuerza pública y el Ejército. No podemos perder territorios, hay entidades federativas en que se ha vulnerado la autoridad. [...] Pero el elemento detonante es a largo plazo, y eso implica una estrategia de reconstrucción institucional completa... (Zepeda, 2009).

El occh fue dado a conocer por el entonces Secretario de Gobernación Federal Juan Camilo Mouriño (fallecido en accidente aéreo el 4 de noviembre de 2008), quien en este primer momento informó de la participación de 2026 militares y 425 agentes federales en el combate a la delincuencia. El Operativo lo justificó como una acción del gobierno federal que protegería a la población en contra de las reacciones del crimen organizado en el marco de la lucha que se estaba implementando: "confiamos en que con este operativo se den resultados positivos que puedan transformar y regresar la seguridad de los chihuahuenses, que el crimen organizado les arrancó a raíz de las acciones que el 
gobierno federal emprende en su contra" (Televisa, 2008). En este mismo marco se encomendó al comandante de la Quinta Zona Militar, Jesús Espitia Hernández, que coordinara la depuración de los cuerpos policiacos de la localidad que pudieran estar involucrados con el crimen organizado.

... el reto que juntos enfrentamos es recuperar todos los espacios que el crimen organizado ha rebasado a la sociedad. Los criminales ante esto seguramente reaccionan y reaccionan con violencia, pero a pesar de esto la voluntad de los chihuahuenses por hacer de su territorio un lugar para vivir en paz es una vocación histórica y mucho mayor. En esta lucha, en esta vocación histórica Chihuahua no estará sola (Chaparro, 2008).

Sin embargo, ante el incremento de la violencia generalizada y la violación a los derechos humanos por parte de elementos policiacos y militares, la exigencia de claridad y transparencia en torno, no solo en los costos, sino en la efectividad y estrategias del Operativo, fueron una constante por parte de diversos sectores de la población. Por citar algunos ejemplos, ya desde principios del 2009 se dio cuenta de al menos una solicitud de información realizada al Instituto Federal de Acceso a la Información y Protección de Datos (IFAI), mismo que confirmó la inexistencia de datos sobre el costo que tendría el occh, en la Secretaría de Gobernación; ello, pese a que fue el titular de dicha dependencia quién lo diera a conocer de manera pública (W Radio, 2009). Cabe señalar que la Secretaría es un ente obligado por la Ley Federal de Transparencia y Acceso a la Información Pública Gubernamental, y el IFAI, como órgano garante de la misma, lejos de obligarla, orientó al interesado a solicitarla ante el Gobierno del Estado. En esta misma tónica, a mediados del 2010, el H. Congreso del Estado de Chihuahua, "exhortó a los mandos de la Operación Coordinada Chihuahua (nombre que recibió posteriormente el occH) a generar indicadores de evolución y diagnóstico de sus operaciones para el dominio público, con el fin de conocer la efectividad de los operativos contra el narcotráfico y crimen organizado" (Ramos, 2010). Esto llama la atención ya que uno de los puntos donde hi- 
cieron énfasis tanto el Plan Nacional de Seguridad (PNS) como las declaraciones oficiales, fue en la colaboración de los tres órdenes de gobierno y sus poderes. Este tipo de solicitudes y exhortos se presentaron en más de una ocasión (La red noticias, 2009).

La ausencia de información y transparencia en torno a los objetivos y estrategias implementadas en estos operativos cobra sentido cuando se da a conocer mediante una investigación periodística que,

Cuando en marzo de 2008 se echó a andar el Operativo Conjunto Chihuahua, la instrucción del secretario de la Defensa Nacional y Alto Mando del Ejército, el ahora general retirado Guillermo Galván, fue contundente: había que utilizar medidas muy duras para cumplir la orden del entonces presidente Felipe Calderón de combatir a los narcotraficantes.

Había que innovar en los métodos de trabajo y de operación. El cumplimiento quedó a la interpretación de los comandantes de las regiones, zonas, guarniciones y aun unidades militares de todo el país. No fueron instrucciones por escrito (Carrasco, 2013).

La anterior situación, señala Víctor Alonso Tadeo Solano, abogado defensor de varios elementos del Ejército procesados por delitos contra la salud y desaparición de personas,

... el surgimiento del "pelotón de la muerte" en la Cine (Comandante de Infantería No Encuadrada), al que se le atribuye por lo menos la desaparición de tres personas en Ojinaga entre junio y agosto de $2008 \ldots$ casi todas las operaciones de la CiNE eran parte del occH y en ocasiones recibía instrucciones directas de la comandancia de la $5^{a}$ Zona Militar; es decir, del general Espitia (Ibíd.).

En septiembre del 2008 se llevó a cabo una reunión de la XI región militar que abarca los estados de Coahuila y Chihuahua. En dicho espacio estuvieron presentes varios jefes militares de la región, entre ellos el general de brigada Manuel de Jesús Moreno Aviña, comandante de la Guarnición de Ojinaga, que informó al titular de la Sedena que como parte de las innovaciones ordena- 
das estaba utilizando camionetas aseguradas a la delincuencia y que eran pintadas y rotuladas como si fueran del Ejército (Ibíd.). El combatir la delincuencia a través de prácticas ilegales generó confusión, temor e incertidumbre en la población, pues seguido cuando se presentaban denuncias públicas en contra de elementos policiacos y/o militares, la respuesta de las autoridades era que no eran ellos los que actuaban "mal", sino delincuentes financiados por narcotraficantes a fin de desprestigiar a las Fuerzas Armadas (El Universal, 2009).

De los resultados del occH, Miguel Ángel Osorio Chong -actual secretario de gobernación- destacó que, en el sexenio de Felipe Calderón, se detuvieron a 106 mil presuntos delincuentes y sólo tres mil están purgando una pena o están en proceso (Índigo, 2013). Víctor Quintana -sociólogo investigador de la UACJ-, en entrevista realizada a principios del 2011, retomando información de la Fiscalía General del Estado y del Instituto Nacional de Estadística y Geografía, señaló que en el 2007 se cometieron 469 homicidios dolosos en todo el estado, mientras que tan solo en los primeros tres años del Operativo, la cifra alcanzó los $11 \mathrm{mil}$. Los diversos delitos se multiplicaron. Ejemplo de ello fue el caso del robo de vehículos, que en el 2007 fue de 9490 y en el 2010 se registraron 30 757; en el 2007 se denunciaron 21 secuestros y en el 2009 190; en tres años hubo 200 desapariciones forzadas en las cuales hay evidencia de participación de elementos del Ejército y policiacos; y tan solo para el caso de Ciudad Juárez se habla de 230000 desplazados por la violencia (La policiaca, 2011). Todo ello sin contar el impacto económico, emocional, psicológico y físico que significó para las familias.

Javier González Mocken, en aquel momento titular de la oficina de Atención de Quejas y Denuncias sobre el Operativo Conjunto Chihuahua, declaró que esta dependencia recibió, tan solo en los primeros nueve meses del Operativo, un promedio de 3 quejas diarias en contra de abusos cometidos por elementos del Ejército Mexicano y la Policía Federal (El Mexicano, 2010). Junto al actuar de dichas instituciones, llama la atención el papel que desempeñó la Comisión Nacional de Derechos Humanos (CNDH), que como instancia oficial encargada de velar por el respeto a los derechos 
humanos tuvo un papel tibio y en no pocas ocasiones encubridor del actuar de los diferentes cuerpos policiacos y militares. De ello da cuenta el diagnóstico que elaboró el Programa Atalaya en torno al desempeño de la CNDH en la atención de quejas contra la Policía Federal (López, 2012).

Como se da cuenta en los párrafos anteriores, a la llegada de Felipe Calderón al gobierno de la república y su declaración de guerra contra el crimen organizado, México entra en una etapa de violencia generalizada la cual se ve agudizada por el incremento en las violaciones a los derechos humanos perpetradas por los diferentes cuerpos policiacos y el Ejército, amparadas en un clima de impunidad. El Centro de Derechos Humanos Miguel Agustín Pro (2013) presentó un informe sobre la situación que guardaron los derechos humanos en el sexenio de Felipe Calderón, dando cuenta de la crisis humanitaria y de derechos humanos que se vivió en este periodo; ejemplo de ello fue el alto índice de asesinatos cometidos, donde sin haber aún un número exacto, oficialmente se contabilizaron 94249 (Centro Pro, 2013: 20). En dicho contexto, y ante la falta de certeza en la información oficial, se generaron varias bases de datos que pretendieron ir registrando los daños causados por esta guerra, en especial los homicidios, así encontramos bases en centros de investigación y académicos, de periodistas, de organizaciones sociales, etcétera. La Presidencia de la República elaboró su propia base de datos para contabilizar los homicidios relacionados con el crimen organizado, conteo del que se omitieron las bajas por parte del Ejército, la Marina y la Policía Federal.

En el documento de presentación de la base de datos, leído por el actual secretario de Gobernación, Alejandro Poiré, se apunta: "89 por ciento de los casos registrados en esta base de datos son resultado de ejecuciones que se definen como homicidios dolosos violentos cometidos presumiblemente para amedrentar a sus rivales o para disciplinar a sus socios" (Centro Pro, 2013: 37).

En dicha base, pese a que no se contabilizó todo el sexenio, se habla de 47515 personas muertas, información que fue reserva- 
da por el gobierno federal por doce años, privando a la sociedad, como señala el Centro Pro, del derecho a la verdad y con ello al de la justicia; más aún, si tenemos en cuenta que a las personas asesinadas o desaparecidas, en la mayoría de los casos se les relacionaba en automático con la delincuencia organizada, imponiéndoles con ello el estigma de delincuentes, sin tener, o tal vez teniendo en cuenta, las implicaciones sociales que ello tendría para la población en general y de manera particular para las víctimas y sus familias, ya que desde el momento mismo de su presentación ante los medios de comunicación eran así etiquetados ante la opinión pública. Por su parte, el INEGI contabilizó 94249 personas asesinadas, ubicando la tasa de homicidios más alta en los varones de entre 25 y 29 años, donde el estado de Chihuahua resultó uno de los más violentos, con una tasa de homicidios de 334.2 por cada cien mil habitantes para el 2010; escenario que se vio agravado por una tasa de impunidad que alcanzó el 99\%, dato aportado por el mismo Gabinete de Seguridad (Centro Pro, 2013: 40). Esta condición facilitó la comisión de violaciones a los derechos humanos. Otros indicadores del clima de violencia que se vivió en el país fueron los desplazamientos internos: para el 2011, la CNDH hablaba de 150 mil personas; y desaparición forzada: la ONU, del 2006 al 2011, registró más de 3000, aclarando que esta categoría solo había sido tipificada en 7 de los 32 estados de la república (Centro Pro, 2013: 41 y 42).

Paralelo a lo anterior, las reformas al sistema penal del 2008 crearon un

... estado de derecho paralelo para las personas que estén acusadas de pertenecer a la "delincuencia organizada", poniendo en práctica con ello el derecho penal del enemigo, claramente antidemocrático por negar la condición de personas a determinados individuos y colectivos (Centro Pro, 2010: 22).

Dicho derecho paralelo, que ahondado con el discurso oficial y mediático que criminalizó a las personas asesinadas y/o detenidas implicó que estas pasaran de ser considerados ciudadanos, con los derechos civiles que ello implica, a ser señalados como presuntos 
delincuentes; justificando, de manera implícita, la violación a sus derechos. Maritza Urteaga y Hugo Moreno (2015), encuentran en el descrédito a las personas, en el "proceso de desciudadanización", como ellos lo nombran, una forma de construcción del enemigo. En este tenor se entienden las justificaciones oficiales de las personas abatidas a manos de elementos policiacos y/o militares que, ante la menor falta, como el no obedecer señalizaciones de alto, eran blanco de fuego. La Secretaría de la Defensa Nacional (Sedena) presentó en el 2012 la cifra de 2893 “'agresores' a quienes las armas del Ejército quitaron la vida durante sus operativos" (Centro Pro, 2013: 46). La CNDH, en sus informes anuales, dio cuenta del incremento de quejas por violaciones a los derechos humanos en contra de la población civil durante el sexenio de Felipe Calderón, entre las que se encuentran detenciones ilegales, allanamientos de morada, desaparición forzada, lesiones, abusos sexuales, ejecuciones, etcétera. A ello hay que añadir que pese a las recomendaciones que emitió el organismo, prevaleció la simulación en su cumplimiento, llegando este al 90 \% (Centro Pro, 2013: 48). En esta misma tónica, organismos internacionales como Human Rights Watch, en sus informes anuales del 2012 y 2013, confirmaron tal situación, señalando que entre el 2007 y 2012 se presentaron 7350 denuncias por abusos militares en contra de civiles, por las cuales solo 38 elementos habían sido juzgados por la Procuraduría General de Justicia Militar. Lo anterior es muestra de la parcialidad en la procuración de justicia que significa la prevalencia del fuero militar en el país, ello pese a que tanto la Suprema Corte de Justicia como la Corte Interamericana habían manifestado que los abusos cometidos por militares debían ser investigados y juzgados por la justicia ordinaria.

El informe del Centro Pro destacó "en el discurso de seguridad de Felipe Calderón, la confusión entre seguridad pública, la seguridad nacional y la seguridad interna, la nula referencia a la seguridad ciudadana, así como la falta de controles civiles a los militares" (Centro Pro, 2013: 45). Las tres primeras privilegiaron por encima del ciudadano a la nación, al Estado o la paz pública, a diferencia de la seguridad ciudadana, que pone el énfasis en los ciudadanos y sus derechos. Es decir, se invierte el orden donde el 
Estado y sus instituciones solo cobran legitimidad al cumplir su función de velar por los derechos de sus habitantes y no al revés.

\section{DISCURSOS QUE DESESTIMAN LOS DERECHOS HUMANOS}

En este sentido, los discursos que generan las instituciones y que reproducimos en la vida cotidiana tienen el poder de llegar a ser fundantes, generando con ello significaciones y reacciones en sectores de la población, y es a través de ellos que obtenemos elementos para reflexionar los acontecimientos y orientar y legitimar nuestras acciones. El discurso que criminaliza, a razón de acción de combate, al crimen organizado, que visualiza como una guerra las estrategias, se finca en un escenario en donde las garantías civiles son vulneradas en aras de la seguridad a partir de lo que la parte que acciona y ejecuta considera como lo legítimo y adecuado.

Los discursos, al ser internalizados, se convierten en sentido común influyendo nuestras visiones. En este mismo orden de ideas, José Nun señala que una interpretación puede verse “... y, en verdad, todo el tiempo estamos 'viendo' interpretaciones. Un conservador, por ejemplo, suele ver en un desocupado a un holgazán; y un socialista, a alguien que necesita ayuda y protección" (Nun, 2014:15). Siguiendo con el autor, lo que nos norma es "el sentido que nos transmiten las instituciones, las ideas fundamentales vigentes acerca de lo que está bien y de lo que está mal, las interpretaciones específicas de la realidad propias de comunidades históricas concretas" (Nun, 2014: 16).

Las luchas por imponer y/o modificar discursos es permanente. Sin embargo, no basta con ser enunciado, creyendo que de manera automática, frente a un contexto determinado, se modificará el sentido. El sentido común es un proceso en constante construcción que con el tiempo se va sedimentando; lo anterior tampoco quiere decir que sea inamovible y de aquí la importancia de los discursos alternos, ya que "agitar es desrutinizar, es hacer que lo normalizado deje de serlo para abrirle paso a nuevas ideas, a nuevas formas de mirar la realidad" (Nun, 2014: 22). En 
este sentido, dice el autor, la intervención cultural en el sentido común supone una toma de posiciones y por ello es conflictiva.

La guerra -entendida así por el mismo presidente de la república-, implicó el estigma a partir de la criminalización de sectores de la población como los que vivían en situación de pobreza, los hombres, y más si son jóvenes, así como los activistas sociales; en torno a ellos fue construido un imaginario de peligrosos, de potenciales delincuentes, de violentos, inconformes, revoltosos; prejuicios que son alimentados especialmente a través de las declaraciones oficiales y los medios de comunicación y que son a la vez reproducidos en la vida cotidiana. Cabe señalar que los prejuicios se van sedimentando no solo en los otros, en la sociedad en general, sino también en las personas objeto de dichas señalizaciones influyendo en su identidad, en su autopercepción, en el reconocimiento de sus capacidades, convirtiéndose así en estereotipos fundantes (Olaza, 2014: 136).

Así, tenemos que los significados culturales van permeando las relaciones sociales y las vivencias de la población. Adoptando la propuesta de Mónica Olaza, quien analiza la situación de racismo que viven las personas de piel negra en Uruguay, señala que un papel del Estado sería la posibilidad de reestablecer la historia de estas personas y el reorientar el discurso. Para ello retoma la idea de sutura propuesta por Grimson, quien plantea una constante reconfiguración cultural; señala que "la sutura se (in) modifica a través de los resultados de la disputa de alteridades por transformar o no, desigualdades de poder" (Olaza, 2014: 137).

... que la cultura no es ni un "anexo" ni "una esfera interesante", es un entramado en el que se pugna por las posibilidades de transformación. La pugna contiene disputas por desigualdades y por su legitimación. De ese modo, el análisis cultural debería realizarse con el análisis de acontecimientos, hechos y procesos sociales y políticos en el que los agentes se sitúan de maneras diferentes respecto del poder y tienen intenciones distintas (Olaza, 2014: 137).

La autora, citando a Quintero Rivera, señala que "la identidad y las diferencias no son solo conceptos sobre los cuales se elabora 
un pensamiento, sino conjuntos emocionales a través de los cuales se desarrollan formas humanas de relacionarse: identidad y diferencia son simultáneamente conceptos y sentimientos" (Olaza, 2014: 138). Así, podemos decir que nos encontramos en un momento donde lo que estaba en cuestión era el sentido y significado que se generaría en tres grandes aspectos: primero, los derechos humanos como un marco ético y legal del actuar público; en segundo lugar, en torno a las personas que han sido señaladas públicamente como delincuentes o han sido blanco de algún hecho delictivo o de violación a sus derechos; y en tercer lugar, hacia quienes los acompañan en su proceso, de manera especial los defensores de derechos humanos. Es decir, fue un escenario donde se contrapuntearon diversos aspectos como la criminalización de sectores de la población frente al principio de inocencia; el estigma frente a la solidaridad. Ante la incertidumbre y la duda, el estigma inhibe actos de solidaridad que se pudieran gestar tanto al interior de las familias como en las redes sociales más amplias; se confrontaron el derecho a la seguridad y los derechos civiles y políticos; se tuvo que decidir entre derechos como la privacidad, la presunción de inocencia, el libre tránsito o la seguridad personal y de propiedad. Se presentó una dicotomía entre los derechos de las víctimas y los derechos de los presuntos responsables; una verdad oficial frente a la verdad de quienes se vieron involucrados en dichas situaciones.

El sentido que se pueda articular al derredor de los derechos humanos y su defensa cobra especial importancia en un contexto de reformas estructurales, que dada su trascendencia tendrán un impacto directo en el deterioro de las condiciones de vida de los mexicanos y la respuesta social que se pueda generar. Ante un clima de violencia e inseguridad creciente se puede posicionar un clima de terror y fragmentación social que inhiben la participación, la solidaridad y la exigencia de un actuar apegado a derecho por parte de la autoridad.

Uno de los aportes de la creciente presencia de organismos de defensa de derechos humanos, y de manera especial los que surgen desde la sociedad organizada, es su influencia en la reconfiguración de nuestra cultura política, encontrando una de sus expre- 
siones en el discurso de los derechos humanos a través de repensar y replantear el valor y la dignidad del ser humano a partir de la discusión de actos o situaciones que se consideran justas o injustas. Se propone, por un lado, el acceso de los acusados a un juicio justo, y por otro, el apego a derecho por los responsables de investigar y procurar justicia; sin embargo, el discurso de los derechos humanos no ha sido suficiente para concretar su plena vigencia.

Para David Fernández, el desafío central en la vigencia de los derechos humanos son los pobres y la pobreza, ya que esta, al colocar a las personas en una posición de mayor vulnerabilidad, se convierte en caldo de cultivo para la violación de derechos fundamentales. Hay en la base de esta reflexión una idea radical de capitalismo que tiende a absolutizar el mercado por encima de la vida de las personas, el comportamiento de las sociedades y la política de los gobiernos. En este sentido, el dominio del capital privado sobre individuos y pueblos enteros es contrario a los derechos humanos, ya que de entrada imposibilita la democracia real como ejercicio básico para un Estado de derecho, quien a su vez es el garante obligatorio de los mismos. El centro de la discusión, señala David Fernández, se encuentra en la noción de persona, ya que esta es el "fundamento de nuestras instituciones políticas y nuestras ideas de lo que debe ser la justicia, la solidaridad y la convivencia social" (Fernández, 1998: 116). En este sentido, señala Fernández, el discurso de los derechos humanos no puede ser neutral, sino que se hace necesario reflexionar desde dónde, cómo, para qué y para quién se habla. La lucha por el respeto de los derechos humanos tiene en sí misma una postura, ya que en este contexto quienes ven violentados sus derechos son principalmente los excluidos y marginados de un sistema. A ello hay que agregar que una apuesta por la dignidad de los despojados no puede concebir a las personas y pueblos de manera fragmentada, con una visión asistencialista o meramente jurídica: debe tener presente que para hacer realidad el discurso de los derechos humanos hay que contemplarlos en su integridad a partir de la esencia de la persona y ser capaz de provocar no solo la respuesta a una demanda inmediata sino la transformación de las condiciones estructurales que inhiben la plena vigencia de 
sus derechos, lo que no se puede lograr a partir de luchas aisladas, sino solo como parte de un proyecto de humanidad.

Consideramos que el discurso de los derechos humanos en México se ha banalizado, ${ }^{2}$ ha pasado a formar parte de la retórica de las instituciones públicas ocultando que son ellas, a partir de su arquitectura institucional, sus normativas y las prácticas que promueven, lo que hace posible la violación a los mismos. Es en este sentido, ubicar los diferentes discursos que se generan en torno al tema de los derechos humanos nos permite ubicar cómo se legitiman diversas prácticas, pero también cómo se generan nuevos enfoques que surgen en diálogo con un contexto y cómo los sentidos y significados se van transformando, ya no desde quienes tendrían que velar por su vigencia, sino desde quienes experimentan sus inconsistencias: "las transformaciones sociales profundas no son obra de los esclarecidos sino de la gente común a la que la realidad de la crisis educa, cambia y organiza" (Almeyra, 2015). En un sentido semejante, Javier Giraldo, S. J., citando a Dussel, señala que "El grito, antes que la palabra de auxilio, es quizás el signo más lejano de lo ideológico". Y más adelante añade

El jay! del dolor primero; el jtengo hambre! ya articulado en un lenguaje, una clase social, un pueblo, un momento de la historia, dice referencia a la realidad o exterioridad de todo sistema constituido. No pueden ser expresiones ideológicas. Son las palabras políticas o primeras, las que instauran nueva totalidad de lenguaje y de formulaciones conceptuales de sentido (Giraldo, 2013: 7).

Lo anterior señala que quienes participan de la experiencia cercana de los que claman y reflexionan su quehacer a la luz del Evangelio participan de un conocimiento situado, siendo el dolor de los oprimidos lo que los mueve a pensar teológicamente y desde ese "iay! de dolor", deciden actuar.

2 Al calificarlo de discurso banalizado nos referimos a un discurso de los derechos humanos que es asumido e integrado por aquellos que, siendo los responsables directos de su vigencia, actúan violentándolo y atribuyen su práctica a la garantía y defensa de estos dejando así, por un lado, sin sentido o, mejor dicho, neutralizando su impacto y por otro haciendo parecer a los defensores de los derechos humanos como defensores de delincuentes. 
Los discursos solo cobran sentido ubicados en un contexto. Recordemos que el sexenio de Felipe Calderón ha sido considerado como uno de los periodos con mayor número de denuncias por violaciones a los derechos humanos en la historia reciente de nuestro país, en aras de un combate frontal al crimen que se instaura en pro de una mayor seguridad. Sin embargo, dicho combate se inserta en un paisaje de reformas estructurales que han puesto en jaque a grandes sectores de la población y el futuro de la nación, como son la reforma laboral, la fiscal y la energética. Lo anterior no quiere decir que dentro de su programa de trabajo el tema de los derechos humanos no estuviera dentro de sus objetivos; en su plan sexenal, en el objetivo número 12 establece "asegurar el respeto irrestricto a los derechos humanos y pugnar por su promoción y defensa” (PND, 2007: 66). Para ello se plantea la necesidad de realizar una serie de reformas legislativas, realizar acciones preventivas y de difusión a la población, así como de concientización a los servidores públicos y establecer sanciones a quienes los violen. Paralelo a este discurso, el presidente, en no pocas ocasiones, aparece en público junto al Secretario de la Defensa Nacional, señalando al Ejército como la única institución digna de confianza dada su lealtad e incorruptibilidad para combatir el crimen y garantizar la seguridad; ello, pese a las advertencias de activistas, organizaciones sociales nacionales e internacionales y académicos sobre los riesgos que implicaba el sacar al Ejército de los cuarteles y cederles el control de diversas instancias de seguridad.

En relación con lo anterior, es necesario dar cuenta del papel que juegan los discursos como ideologías, ya que en ellos también se sustentan las políticas públicas. Desde el momento en que se plantea una problemática está presente un discurso ideológico que orienta su visión y formas de acción: "por un lado, pretende brindarnos una interpretación racional de la realidad y, por el otro, nos propone un programa de acción fundado en esa interpretación" (Nun, 2014: 18).

En tal sexenio, el discurso oficial de los derechos humanos se mantuvo subordinado al de la seguridad pública. 
Hoy la delincuencia pretende atemorizar e inmovilizar a la sociedad y al Gobierno; la inseguridad pública amenaza a todos y se ha convertido en el principal problema de estados, ciudades y regiones enteras. Una de las tres prioridades que voy a encabezar en mi Gobierno es, precisamente, la lucha por recuperar la seguridad pública y la legalidad; las instituciones responsables de la seguridad pública requieren transformaciones profundas para incrementar sustancialmente su eficacia... Sé, que restablecer la seguridad no será fácil ni rápido, que tomará tiempo, que costará mucho dinero, e incluso y por desgracia, vidas humanas. Pero ténganlo por seguro, esta es una batalla en la que yo estaré al frente, es una batalla que tenemos que librar y que unidos los mexicanos vamos a ganar a la delincuencia. Pongamos fin a la impunidad, a la impunidad de los delincuentes que amenazan nuestras vidas y familias (Calderón, 2006).

Felipe Calderón se refirió en varias ocasiones a su estrategia de seguridad como una guerra, recordemos la entrevista que le realiza Jorge Zepeda Paterson (2009), donde declaró: "El crimen organizado busca el control territorial. Será una guerra sin cuartel porque ya no hay posibilidad de convivir con el narco. No hay regreso; son ellos o nosotros".

A tal grado se dio dicha subordinación que incluso en el discurso que pronunció el Presidente de la República en el último informe de Raúl Plascencia, Presidente de la Comisión Nacional de Derechos Humanos, el tema de la seguridad prevaleció y minimizó la situación de violación a los derechos humanos, pese a que durante todo su sexenio fue una demanda que mantuvieron tanto organismos nacionales como internacionales.

... pero, también, y hay que reconocerlo en toda su magnitud, también, en este periodo se ha vivido enfrente de uno de los más grandes desafíos que le haya tocado enfrentar al país. Como decía, un fenómeno delincuencial de enorme magnitud y agresividad, criminales que secuestran, que roban, que extorsionan a los mexicanos de bien y que son la mayor amenaza, a mi juicio, para los derechos de las personas (Calderón, 2012). 
En la entrevista realizada, Jorge Zepeda cuestiona a Felipe Calderón sobre los daños colaterales ${ }^{3}$ que su lucha contra el crimen estaba generando, en especial en lo que respecta a los derechos humanos, a lo que el Presidente respondió: "me parece que los costos asociados a combatir la inseguridad con determinación son siempre menores" (Zepeda, 2009), insistiendo en que la mayor amenaza a los derechos humanos es la criminalidad. El riesgo principal de este tipo de discursos es la confusión que se puede generar entre la población al momento de reflexionar sobre los asuntos que le aquejan, al querer ubicar a los responsables de su seguridad y de las situaciones que la ponen en riesgo, así como de las formas de hacerles frente.

La guerra contra la criminalidad en todo momento se sostuvo bajo el argumento de recuperar la seguridad y la tranquilidad de los mexicanos. Sin embargo, los "daños colaterales" causaron una gran cantidad de personas muertas, desaparecidas, desplazadas y en no pocas ocasiones fueron señalados los mismos elementos del Estado como los responsables. José Nun se pregunta qué pasa cuando no hay coherencia entre lo que dicen y hacen las instituciones, a lo que él mismo responde al señalar que la gente, al no sentirse contenida, pierde confianza en sus semejantes y en las instituciones llevándola a la alienación, "lo cual confirma que la ética objetiva es la que nos ayuda a vivir en sociedad, naturalizando interpretaciones que es más fácil violar que transformar" (Nun, 2014: 16).

Uno de los impactos que podemos señalar, más allá de la desorientación primera, es el estigma que se genera en contra de los que son señalados y presentados públicamente como criminales, dificultando con ello la solidaridad que se pueda dar al interior de las familias y con las redes de conocidos y amigos. Ello podría ocasionar una polarización social, así como un repliegue en su actuación. Por un lado, debemos tener presente que lo que vivimos y la forma en que lo leemos y damos sentido se encuentra mediado por una serie de discursos, influyendo así en las posibilidades

3 Daño colateral es un término utilizado por diversas fuerzas armadas para referirse al daño no intencional o accidental producto de una operación militar (USAF Intelligence Targeting Guide, 1998: 180). 
y formas de procesar y reaccionar frente a los acontecimientos; y por otro, si bien es un derecho humano de primer orden el vivir en un ambiente de paz y seguridad, no hay que olvidar que el responsable primero de ello es el Estado y por tanto resulta incoherente que violente los derechos de las personas en aras de la seguridad; ello sería dar entrada a un Estado de terror, que ante el justificante de cumplir con su razón de ser, podría imponerse por encima de la misma ley colocándonos además ante un falso debate entre seguridad y derechos humanos.

Ciertamente, en algunos casos hubo una aceptación de hechos que se suscitaron. Sin embargo, fueron minimizados al ser considerados actos aislados por parte de algunos indignos servidores públicos: "... desafortunadamente, es cierto, se han dado casos de actos violatorios de los derechos humanos, algunos de ellos muy graves... el Gobierno mexicano no solo los ha condenado enérgicamente, sino que ha procedido legalmente en contra de los autores de los mismos, ante los tribunales competentes" (Calderón, 2012). Como si la estructura institucional y sus normas quedaran al margen de dichas prácticas, lo que pone en una situación de mayor vulnerabilidad e incertidumbre en el qué hacer y a dónde acudir a quienes han sido víctimas de violaciones a sus derechos humanos.

Dado que el principal garante de los derechos humanos ${ }^{4}$ es el Estado, las violaciones a estos son consideradas como actos de autoridad; actos que, en el contexto de la guerra contra el crimen

4 La CNDH (2016), define a los derechos humanos como "el conjunto de prerrogativas sustentadas en la dignidad humana, cuya realización efectiva resulta indispensable para el desarrollo integral de la persona. Este conjunto de prerrogativas se encuentra establecido dentro del orden jurídico nacional, en nuestra Constitución Política, tratados internacionales y las leyes", reconociendo a las autoridades como las obligadas de su protección y garantía. El TSJDF por su parte los define como "derechos inherentes a todos los seres humanos, sin distinción alguna de nacionalidad, lugar de residencia, sexo, origen nacional o étnico, color, religión, lengua, o cualquier otra condición", señalando que es el derecho internacional quien establece la obligación de los gobiernos de promoverlos y protegerlos. Por su parte, Máximo Pacheco (1998), quien fuera juez de la CIDH, prefirió nombrarlos como derechos fundamentales de la persona humana, con lo que se refería a que "toda persona humana posee derechos por el hecho de serlo y estos deben ser reconocidos y garantizados por el Estado sin ninguna discriminación social, económica, jurídica, política, ideológica, cultural o sexual. Pero, al mismo tiempo, quiero destacar que esos derechos son fundamentales, es decir, que se encuentran vinculados con la idea de dignidad de la persona humana". 
organizado, fueron promovidas por un discurso bélico. En dichas violaciones participaron, entre otros, elementos de la Policía Federal, el Ejército y la Marina. Se pretendió una lucha por la seguridad y el cumplimiento de la ley, violando la misma ley por aquellos que debieran garantizarla. Recordemos que el Ejército no está capacitado ni facultado para realizar funciones de seguridad, aunado a una serie de prácticas y medidas que se fomentaron en aras de la seguridad que en sí mismas ya eran violatorias a los derechos humanos, como el establecimiento de retenes, la realización de cateos aleatorios, la revisiones físicas a las personas y sus pertenencias, la permanencia del fuero militar, los diversos intentos por legalizar y ampliar las facultades del Ejército y la Marina, el clima de impunidad, reformas que criminalizaron la protesta social, así como actos tímidos y en ocasiones negligentes por parte de la CNDH, órgano que, aunque no vinculatorio en sus resoluciones, es el facultado legalmente para recibir y atender quejas sobre dichas violaciones.

Dado lo anterior no se puede seguir hablando de actos aislados, del actuar de ciertos malos elementos que con una llamada de atención van a corregir su proceder, sino que la violación a los derechos humanos se convierte en una política pública que queda implícita en el actuar de un gobierno cuando esta es fomentada por acción, omisión o aquiescencia de sus instituciones. Todo acto como todo discurso no es neutral, tiene una intencionalidad. Así, podemos señalar que dentro de las implicaciones del actuar de las autoridades se encuentra, por un lado, que la sociedad ante un clima de violencia e inseguridad ha ido cediendo parte de sus derechos y libertades a cambio de una supuesta seguridad, justificando y tolerando la injerencia militar y policiaca en su vida cotidiana y en la de las instituciones civiles; por otro lado, que al negar una práctica institucionalizada de violación a los derechos humanos, paralelo a que es sembrado un clima de terror, se genera una desmovilización social y se controlan posibles actos de denuncia y solidaridad ciudadana, dificultando con ello la labor de los defensores de los derechos humanos al colocarlos como defensores de delincuentes. 
Diluir u ocultar la discusión sobre los derechos humanos en el de la seguridad y combate al crimen es dar pie a una legitimación intrínseca de su violación, de ahí la importancia de no desligar los discursos de los contextos en que son generados. En este sentido, el Operativo Conjunto Chihuahua se desprendió de la Iniciativa Mérida, la cual se enmarca en la estrategia de seguridad de la frontera México-Estados Unidos y la garantía del mercado.

En México, desde los años ochenta se han implementado una serie de medidas económicas neoliberales que han llevado a una creciente pobreza y marginación, mismas que cobraron especial énfasis en el sexenio de Calderón. En dicho periodo se dio mayor poder a compañías nacionales y transnacionales, que en complicidad con una clase política, buscaron despojar a comunidades enteras de sus recursos y territorios sembrando el terror en sus habitantes. En este sentido, al hablar de seguridad y combate al crimen es necesario aclarar que no estamos hablando de cualquier seguridad y de cualquier combate, sino de uno que ha arrojado miles de desaparecidos, desplazados, torturados, detenidos ilegalmente; donde tanto organismos nacionales como internacionales han documentado la participación directa de las fuerzas de seguridad, lo que nos puede estar hablando de una política de seguridad no de las personas que habitan este país, sino de los intereses de un mercado que somete a pueblos enteros a cambio de su seguridad.

Uno de los discursos que más se han criticado al sexenio de Felipe Calderón fue la atribución del clima de violencia que recorrió al país a pleitos entre grupos criminales, dando por sentado que quienes murieron en este periodo estaban relacionados indiscutiblemente con la delincuencia, justificando así la ausencia de investigaciones judiciales. Una muestra de ello fue la declaración que dio desde Tokio, Japón, el 2 de febrero del 2010, cuando se enteró que un día antes habían masacrado a un grupo de jóvenes estudiantes en una colonia de Ciudad Juárez, donde "atribuyó el ataque a un pleito 'de pandillas' y dijo que se fortalecerían las acciones de los tres niveles de gobierno para tener una estrategia integral contra el crimen organizado" (CNN, 2010). Despertó con ello tal indignación que llevó a una gran movilización social que lo 
obligó a venir a la ciudad y corregir, al menos en este caso, su discurso, y a reconocer que no eran delincuentes sino estudiantes.

Hay que resaltar que dicho discurso de criminalización fue asumido por los diferentes órdenes e instancias de gobierno durante este sexenio, como lo muestran las declaraciones tanto del teniente coronel Julián Leyzaola, Secretario de Seguridad Pública Municipal en Ciudad Juárez, al señalar que "es necesario procesar a los criminales, tratarlos como lo que son, hablar su lenguaje. Debemos confrontarlos y contraatacar" (Martínez, 2012). En la misma nota los refiere como "escoria". Por su parte, Fernando Gómez Mont, Secretario de Gobernación, en dicho sexenio regañó a los periodistas de la ciudad cuando le cuestionaban por la falta de resultados en materia de seguridad y los abusos cometidos por elementos de la Policía Federal y el Ejército, a lo que respondió: "si siguen fomentando esta división entre la ciudadanía y el gobierno, ustedes causan la violencia... ¿Han visto cuántos policías han muerto en Juárez protegiendo a los juarenses? ... ¿por qué le cobra a la autoridad una factura de la violencia, si [los narcotraficantes] se están matando entre ellos?" (Villalpando, 2010). Otro caso fue el del general Jorge Juárez Loera, quien fuera responsable del Operativo Conjunto Chihuahua, al declarar "a mí me gustaría que los periodistas cambiaran su nota y donde dicen 'un muerto más', dijeran 'un delincuente menos', ojalá lo piensen, y los dueños de los periódicos y los editorialistas empleen bien el idioma” (El Ágora, 2008).

Dar cuenta de cómo se vio trastocada la vida de la población en el sexenio de Felipe Calderón es aún un tema pendiente. Hay varias investigaciones que han dado cuenta de los cambios que vivió la ciudad durante dicho sexenio pero aún falta analizar si este periodo influyó de alguna manera la forma de relacionarnos entre ciudadanos y las autoridades a partir de la resemantización que se impulsó, planeado o no, en torno a la vigencia de los derechos humanos y el actuar de las autoridades en la procuración de justicia; es decir, si podemos, por tanto, hablar de una reconfiguración político-cultural. 


\section{FUENTES CITADAS}

Almeyra, Guillermo (marzo 1, 2015). “Syriza: ¿tregua o traición?”. La jornada. Opinión. hhtp://www.jornada.unam.mx/2015/03/01/opinión/020a2pol Calderón, Felipe (diciembre 1, 2006). Palabras al pueblo de México desde el Auditorio Nacional. http://calderon.presidencia.gob.mx/2006/12/ palabras-al-pueblo-de-mexico-desde-el-auditorio-nacional/ (consultado el 10 de junio de 2014).

Carrasco, Jorge (enero 12, 2013). "Las rémoras del Operativo Conjunto Chihuahua". Revista Proceso. http://www.proceso.com.mx/?p=330700 (consultado 9 de agosto de 2013).

Centro de Derechos Humanos Miguel Agustín Pro-Juárez, A.C. (2010). Sociedad amenazada. Violencia e impunidad, rostros del México actual. México.

Centro de Derechos Humanos Miguel Agustín Pro-Juárez, A.C. (2013). Transición traicionada: los derechos humanos en México durante el sexenio 2006-2012. México.

Chaparro, Ana (marzo 28, 2008). Un reto el "Operativo Conjunto Chihuahua”, dice Camilo Mouriño. El Mexicano. Ciudad Juárez, México. http:// www.oem.com.mx/esto/notas/n643488.htm (consultado el 9 agosto de 2013).

CNDH. ¿Qué son los derechos humanos? http://www.cndh.org.mx/Que_ son_Derechos_Humanos (consultado el 17 de mayo de 2016).

Desmesura (febrero 3, 2012). Discurso del Presidente Felipe Calderón durante el informe de la cNDH. http://desmesura.org/discursos/losderechos-humanos-en-el-discurso-del-presidente-felipe-calderoncndh (consultado 30 de marzo de 2016).

El Ágora (julio 2, 2008). "Cambian a responsable de Operación Chihuahua”. El Ágora. http://www.elagora.com.mx/Cambian-a-responsablede-Operacion,5626.html (Consultado 17 de agosto 2014)

Escalante Gonzalbo, Fernando (enero 1, 2011). "Homicidios 2008-2009. La muerte tiene permiso". Nexos. http://www.nexos.com.mx/?p=14089 (consultado el 16 de mayo de 2016).

Expansión (febrero 9, 2010). "Calderón irá a Ciudad Juárez a reunirse con familiares de jóvenes asesinados". Expansión. Nacional. http://expansion.mx/nacional/2010/02/09/felipe-calderon-estara-en-ciudad-juarez-el-jueves (consultado 30 de marzo de 2016). 
Fernández, David (1998). "El reto de los derechos humanos en México a cincuenta años de su promulgación”. Derechos Humanos, órgano informativo de la Comisión de Derechos Humanos en el Estado de México. No. 34 pp. 113-120. México.

Giraldo, Javier (2013). La teología frente a otra concepción del conocer. Editorial Códice Ltda. Bogotá, Colombia.

Human Rights Watch (2012) Informe mundial 2012. http://www.hrw.org/ sites/default/files/related_material/wr2012spwebwcover-1.pdf (consultado el 11 de junio de 2014).

Human Rights Watch (2013) World report 2013. https://www.hrw.org/sites/ default/files/wr2013_web.pdf (consultado el 11 de junio de 2014).

Índigo Staff (agosto 26 de 2013). “Chong us. Calderón”. Revista Reporte Índigo. http://www.reporteindigo.com/reporte/mexico/chong-vs-calderon

Larednoticias.com (febrero 8, 2009). "Opacidad en Operativo Conjunto, no informan de operaciones y resultados: Fernando Álvarez". La red noticias. http://www.larednoticias.com/noticias.cfm?n=21253 (consultado el 29 de agosto de 2013).

López, Antonio (2012). Desempeño de la CNDH en la atención de quejas contra la policía federal. ITAm. Fundar. Programa Atalaya. Análisis académicos de la CNDH y CDHDF.

Martínez, Arturo (marzo 26, 2012). "La policía de Ciudad Juárez enfrenta mortales ataques por parte de El Tin Tan”. Amigos de Tamaulipas. http://amigosdetamaulipas2.mforos.com/1832982/10593281-la-policia-de-ciudad-juarez-enfrenta-mortales-ataques-por-parte-de-eltin-tan/

Merino, José (junio 1, 2011). Los operativos conjuntos y la tasa de homicidios: una medición. Nexos. http://www.nexos.com.mx/?p=14319 (consultado el 16 de mayo de 2016).

Noticieros Televisa México (marzo 27, 2008). "Anuncian Operativo Conjunto Chihuahua”. Noticieros Televisa. http://www.esmas.com/noticierostelevisa/mexico/717671.html (consultado el 4 de septiembre de 2013).

Nun, José (2014). "El sentido común y la construcción discursiva de lo social”, en Culturas políticas y políticas culturales. Pp.15-26. Ediciones Boll Cono Sur. Buenos Aires, Argentina. 
Olaza, Mónica (2014). "Políticas públicas y cultura política. Reflexiones posibles para desnaturalizar prejuicios, estereotipos y racismo", en Culturas políticas y políticas culturales. Pp.133-144. Ediciones Boll Cono Sur. Buenos Aires, Argentina.

Pacheco, Máximo (1998). "El concepto de derechos fundamentales de la persona humana”, en Liber amicorum, Héctor Fix-Zamudio. Volumen I. CIDH.

Plan Nacional de Desarrollo 2007-2012 (2007) Poder Ejecutivo Federal, México.

Ramos, Jessica (julio 21, 2010). "Pide Congreso informe de acciones de la Operación Coordinada Chihuahua". xHEPL. http://www.xepl.com.mx/ completa1.php?i=49626 (consultado el 10 de agosto de 2013).

Redacción (julio 13, 2009). "Algo grave, bajo el techo de Juárez". El Universal. http://www.eluniversal.com.mx/nacion/169662.html

Redacción (enero 7, 2010). "Se registran 4 quejas diarias contra Ejército". El Mexicano. http://www.oem.com.mx/elmexicano/notas/n1469059. htm (consultado el 17 de junio de 2014).

Redacción (abril 6, 2011). "Investigador advierte que Operativo Conjunto dispara violencia". La policiaca, la nota roja de México http://www. lapoliciaca.com/nota-roja/investigador-advierte-que-operativo-conjunto-chihuahua-dispara-violencia/ (consultado el 6 de septiembre de 2013).

Ruiz, Laura y Urizar, Eric (2014). "Impacto psicosocial de la violencia en Ciudad Juárez dentro del marco del Operativo Chihuahua 20082012”. Ciudad Juárez, México. (Sin publicar).

TSJDF. ¿Qué son los derechos humanos? http://www.derechoshumanosdf.gob.mx/es/DOCDH/Definicion (consultado el 17 de mayo de 2016).

Urteaga, Maritza y Moreno, Hugo. (2015). “Corrupción e impunidad versus justicia y derechos humanos en México”. En (Valenzuela, José, coord.) Juvenicidio. Ayotzinapa y las vidas precarias en América Latina y España. NED, ITESo y Colef. México.

Secretary of the Air Force (1998). USAF Intelligence targeting guide. http:// www.davi.ws/doc/afpam14-210.pdf (consultado el 17 de mayo de 2016).

W Radio (febrero 25, 2009). Confirma IFAI inexistencia de datos de operativo Chihuahua en Segob. W Radio. Nacional. http://www.wradio. 
com.mx/noticias/actualidad/confirma-ifai-inexistencia-de-datosde-operativo-chihuahua-en-segob/20090225/nota/768946.aspx

Villalpando, Rubén (junio 2, 2010). "Reprocha Gómez Mont a la prensa falta de ayuda para recuperar la paz en Juárez". La Jornada. Política. http://www.jornada.unam.mx/2010/06/02/politica/019n1pol\#texto (consultado el 17 de junio de 2014).

Zepeda, Jorge (febrero 27, 2009). "El crimen es la mayor amenaza a los derechos humanos". El Universal. Nación. http://www.eluniversal.com. mx/nacion/166067.html (consultado el 26 de febrero de 2015). 